\title{
(Bio)chemical reactions during high pressure/high temperature processing affect safety and quality of plant-based foods
}

Iesel Van der Plancken ${ }^{1}$, Lise Verbeyst ${ }^{1}$, Kristel De Vleeschouwer ${ }^{1}$, Tara Grauwet $^{1}$, Raija-Liisa Heiniö2 ${ }^{2}$ Fiona A. Husband ${ }^{3}$, Martina Lille², Alan R. Mackie $^{3}$, Ann Van Loey ${ }^{1}$, Kaarina Viljanen ${ }^{2}$, Marc Hendrickx ${ }^{1 *}$

\footnotetext{
1 Laboratory of Food Technology and Leuven Food Science and Nutrition Research Centre (LFoRCe), Department of Microbial and Molecular Systems (M2S), Katholieke Universiteit Leuven, Kasteelpark Arenberg 22 box 2457, 3001 Leuven, Belgium.
}

${ }^{2}$ VTT Technical Research Centre of Finland, P.O. Box 1000, FI-02044 VTT, Finland

${ }^{3}$ Structuring Food for Health Programme, Institute of Food Research, Norwich Research Park, Colney, UK

* Corresponding author: prof. Dr. Marc Hendrickx, Laboratory of Food Technology and Leuven Food Science and Nutrition Research Centre (LFoRCe), Department of Microbial and Molecular Systems (M2S), Katholieke Universiteit Leuven, Kasteelpark Arenberg 22 box 2457, 3001 Leuven, Belgium.

Marc.hendrickx@biw.kuleuven.be

Tel +32 16321572

Fax +3216321960 


\begin{abstract}
In recent years, the range of equipment and applications for high pressure pasteurization has gradually increased on the European market. Sterilization under conditions of elevated pressures is in the pipeline, albeit at the research level. Knowledge on the effect of high pressure/high temperature processing on food safety and quality attributes is still too limited. This review discusses recent progress made in understanding the impact of high pressure/high temperature processing on food safety and quality attributes of fruit and vegetable based products, within the EU FP6 integrated project NovelQ.
\end{abstract}

\title{
Introduction
}

While high pressure pasteurisation is steadily finding its way into the food industry, with a gradual increase in high pressure equipment and applications, high pressure/high temperature (HP/HT) processing intended to inactivate microbial spores, is still in the research stage. This type of process would typically consist of (i) a pre-heating phase at ambient pressure to a relatively low initial temperature (below $100^{\circ} \mathrm{C}$ ), followed by (ii) a fast temperature increase to the process temperature (allowing spore inactivation) accompanying the pressure build-up (typically up to $600 \mathrm{MPa}$ ), (iii) a relatively short holding phase (up to $5 \mathrm{~min}$ ) and finally (iv) a fast cooling phase induced by pressure release. In addition to the stricter requirements with regard to equipment design that are necessitated by the additional process parameter temperature, the incomplete understanding of the combined effect of pressure and temperature stalls the implementation of this technology in food industry. One of the major stumbling blocks in that respect is the correct experimental set-up to obtain reliable kinetic data.

At the beginning of the NovelQ project (March 2006), the status quo of the scientific knowledge on the effect of high pressure processing was captured in a special issue of Trends in Food Science and Technology in a series of review papers covering a broad range of topics (Wilson, Dabrowski, Stringer, Moezelaar, \& Brocklehurst, 2008; Oey, Lille, Van Loey, \& Hendrickx, 2008a; Oey, Van der Plancken, Van Loey, \& Hendrickx, 2008b; Sila et al., 2008; Delgado, Rauh, Kowalczyk, \& Baars, 2008; Van der Plancken, Grauwet, Oey, Van Loey, \& Hendrickx, 2008). At that time, most studies were focussed on the effect of high pressure pasteurisation at moderate temperature and only a few studies had been performed on the effect of high pressure on food attributes at elevated temperature. The current review paper discusses the progress made within the NovelQ project in the field of HP/HT processing on fruit and vegetable based products and its effect on food safety and quality related (bio)chemical reactions. Within this project, major attention was given to establishing and applying a protocol for kinetic studies under HP/HT conditions with maximal control of the processing variables.

\section{Methodological approach for kinetic studies under HP/HT conditions}

When performing a kinetic study, process parameters need to be, if not kept constant, at least documented as completely as possible. Rate constants strongly depend on pressure and temperature, both critical process parameters in HP/HT processing. Therefore, incorrectly assuming that process parameters are constant or inadequate knowledge of the temperature, pressure history will lead to incorrect estimates of the kinetic parameters (e.g. rate constants, activation energy and activation volume). Moreover these cannot then be extrapolated to different equipment (Van der Plancken et al., 2008). This is even more pertinent, when larger scale high pressure vessels are used, in which major temperature non-uniformity may arise (Grauwet, Van der Plancken, Vervoort, Van Loey, \& Hendrickx, 2010; Landfeld et al., 2010). 
In the NovelQ project, a strategy was employed involving capturing of adiabatic heating during a fast pressure build-up (e.g. $600 \mathrm{MPa} / \mathrm{min}$ ) to attain a specified temperature at the given pressure level and keeping this constant by providing additional heat (Figure 1). This approach is appropriate for fast pressure-induced changes, as already significant changes can occur during the dynamic pressure build-up phase. Depending on the type of equipment, pressure-transferring medium (e.g. water or propylene glycol) and isolation (e.g. poly-oxy-methylene) used, these conditions of constant pressure and temperature can be retained during a short or a longer period of time. This approach nevertheless requires adequate monitoring of the pressure and temperature in the sample, so that these can be properly taken into account during data analysis in order to obtain good estimates for the kinetic parameters.

\section{Safety}

When developing a process, one first has to assure that it will result in safe products, both at the microbial and the (bio)chemical level. The former will not be discussed in the current paper. Since the review paper by Wilson et al. (2008), some kinetic studies on spore inactivation by HP/HT processing have been published that also paid attention to attaining isothermal conditions necessary for proper parameter estimation (e.g. Ahn, Balasubramaniam \& Yousef, 2007; Zhu, Naim, Marcotte, Ramaswamy \& Shao, 2008; Ramaswamy, Shao \& Zhu, 2010; Shao, Zhu, Ramaswamy \& Marcotte, 2010; Reineke, Mathys \& Knorr, 2011). This section, however, focuses only on (bio)chemical reactions occurring under conditions of high pressure and high temperature that affect the safety of the food, in particular for the two case-studies of existing food allergens and of acrylamide formation .

\section{Acrylamide formation}

Thermal processing of carbohydrate-rich foods, such as potato and cereal products can lead to the formation of the potential human carcinogen acrylamide, predominantly through the Maillard reaction between the amino acid asparagine and a reducing sugar. The Maillard reaction is also responsible for the formation of desired as well as undesired colour and flavour compounds and is therefore considered one of the most important chemical reactions in determining the quality of heated foods.

Limited information is available on acrylamide formation during HP/HT processing. Exploratory studies, mostly restricted to specific Maillard reaction products and limited in processing conditions (with regard to the number and range of temperature and pressure levels), indicated a retarding effect of high pressure on the Maillard reaction (Hill, Ledward, \& Ames, 1996; Schwarzenbolz, Klostermeyer, \& Henle, 2000; Frank, Heberle, Schieberle, \& Hofmann, 2002; Deters, Hofmann, \& Schieberle, 2003; Heberle, Schieberle, \& Hofmann, 2003; Moreno, Molina, Olano, \& Lopez-Fandino, 2003; Alt \& Schieberle, 2005; Jaeger, Janositz, \& Knorr, 2010).

Within the NovelQ project, the impact of HP/HT-conditions (100-115 $\left.{ }^{\circ} \mathrm{C}, 400-700 \mathrm{MPa}, 0-60 \mathrm{~min}\right)$ on the different stages of the Maillard reaction was elucidated in equimolar asparagine-glucose model systems, measuring the concentration of acrylamide, reactants, hydroxymethylfurfural, organic acids, and melanoidins, as well as $\mathrm{pH}$ before and after treatment. The retarding effect of high pressure on the overall Maillard reaction was demonstrated, although the rate at which acrylamide was formed strongly depended on the buffer system used and the temperature and pressure dependence of its acid dissociation constant $\left(\mathrm{pK}_{\mathrm{a}}\right)$. The stronger retardation in phosphate buffer compared to 2-(N-morpholino)ethanesulfonic acid (MES) buffer was attributed to the greater (estimated) pH drop (Bruins, Matser, Janssen, \& Boom, 2007; Byrne \& Laurie, 1999), although probably partly counterbalanced by the enhancing effect of phosphate ions on the Maillard reaction 
(Bell, 1997; Rizzi, 2004). Because of the strong retardation in acryl amide formation, only data points at long treatment times exceeded the detection limit, making it impossible to perform kinetic modelling. However, based on the results obtained in model systems, it could be demonstrated that maximal acrylamide concentrations generated ( $1700 \mathrm{ppb})$ during a $60 \mathrm{~min}$ HP/HT-treatment at 115 ${ }^{\circ} \mathrm{C}$ and $600 \mathrm{MPa}$ are considerably lower than the maximal ones during a conventional (i.e. at atmospheric pressure) heat treatment $\left(\sim 6500 \mathrm{ppb}\right.$ after $50 \mathrm{~min}$ at $\left.115^{\circ} \mathrm{C}\right)$. Moreover, the time frame that is relevant for high pressure sterilization applications is much shorter (3-5 min holding time at $121^{\circ} \mathrm{C}$ ) than the frame selected in the study for kinetic purposes. Based on these considerations and the fact that only high water content products are relevant for high pressure processing applications, the authors concluded that acrylamide formation is not expected to pose a major hazard to this type of products (De Vleeschouwer, Van der Plancken, Van Loey, \& Hendrickx, 2010).

\section{Allergens}

Allergens pose another safety risk for susceptible consumers. It is known that the secondary and tertiary structure of food allergens is crucial to their allergenic potential. Therefore, processing techniques affecting this structure, such as HP treatment, have the potential to reduce the allergenicity of foods. Several studies have been performed on the effect of HP at ambient to moderate temperature on different allergens from plant origin, such as from rice (Kato et al., 2000), apple (Meyer-Pittroff, Behrendt \& Ring, 2007), celery (Jankiewicz et al., 1997; Houska et al., 2009), carrot (Heroldova et al., 2009), soybean (Peñas et al., 2011), and birch pollen (which contains an allergen that is highly cross reactive with major allergens from a wide range of plant food allergens) (Setinova et al., 2009), but to our knowledge not at elevated temperatures (above $60^{\circ} \mathrm{C}$ ).

In the NovelQ project, the effects of temperature and/or high pressure (150-800 MPa, $10 \mathrm{~min}$ ) treatments were studied on three selected, purified plant allergens: Ara h 2,6 (peanut 2S albumins) and the predominant apple allergens, Mal d 1 and Mal d 3 . High pressure treatment had little effect on the structure of the 'prolamin-fold' proteins Ara $\mathrm{h} 2$ and 6 from peanut at either room temperature or at $80^{\circ} \mathrm{C}$, as shown by FTIR-spectroscopy. The native $\alpha$-helix structure remained stable. In the case of apple Mal d 3, changes in secondary structure due to pressure processing at $80^{\circ} \mathrm{C}$ were observed and attributed to the temperature, rather than the pressure. These changes were also reflected in the antibody recognition of Mal $\mathrm{d} 3$. The heterologously expressed Mal $\mathrm{d} 1$ showed small changes in secondary structure following high pressure treatment at $20^{\circ} \mathrm{C}$ with rather more alteration at $80^{\circ} \mathrm{C}$. A later study by Somkuti, Houska and Smeller (2011) following online the unfolding of Mal d $1(75 \mathrm{mg} / \mathrm{ml})$ in a diamond anvil cell indicated the irreversible unfolding of the protein at $150-250 \mathrm{MPa}$ at $30^{\circ} \mathrm{C}$ followed by aggregation. The secondary structure of Mal $\mathrm{d} 1$, whilst less stable, was able to refold after heat treatment and showed no consistent changes after treatment. The changes that were observed were attributed to changes in aggregation state and thus concentration. However, these observations may not be representative of what happens when the allergens are heated in the fruit, where the chemical environment of the proteins is very different (Johnson et al., 2010).

Therefore, Husband et al. (2010) studied the impact of thermal and high pressure processing on the immunoreactivity of the two main allergens in apple (Mal d1 and Mal d 3), as well as the Bet $v 1$ homologue Api $\mathrm{g} 1$ in celeriac. The results showed that Mal $\mathrm{d} 1$ was subject to chemical modification as soon as the apple tissue was disrupted although it was remarkably resistant to both thermal (10 min at $\left.115^{\circ} \mathrm{C}\right)$ and $\mathrm{HP} / \mathrm{HT}\left(10 \mathrm{~min}\right.$ at $115^{\circ} \mathrm{C}$ and $700 \mathrm{MPa}$ ) processing. This observation was confirmed in vitro using human sera. This is in contrast to the Bet $v 1$ homolog from celeriac, Api $g 1$ that was susceptible to thermal processing at either pressure. The other major allergen in apple, Mal $d 3$ was found to be resistant to chemical modification and thermal processing in apple, which is in contrast to its behaviour in solution. These authors showed that pectin protected Mal d 3 from thermal 
denaturation in solution and is one possible candidate for the protective effect of the fruit matrix towards heat susceptibility. The combination of pressure and temperature significantly reduced its immunoreactivity. The conclusion to be drawn from these results is that HP/HT processing is an effective method to reduce the allergenicity of both apple and celeriac but for allergen-specific differing reasons. Mal d 1 will have its allergenic potential reduced by disruption of the apple cell structure either prior to or during the processing. The celeriac allergen Api g 1 will have its immunoreactivity reduced by thermal processing at ambient or elevated pressure, while the apple allergen Mal d 3 requires HP/HT processing. In conclusion, HP/HT processing makes apple safer to eat as the Mal $\mathrm{d} 3$ is modified by the process and the Mal $\mathrm{d} 1$ allergen is modified by the disruption of the tissue. It is difficult to draw a general conclusion on the effect of HP/HT processing, as there is clearly an effect of the matrix on allergen inactivation and the mechanism seems to differ between allergens.

\section{Quality}

Once processing conditions have been established that render a safe product, it is key to optimize the process with regard to product quality, as this will be the criterion by which the technology will be evaluated by the consumer, who always expects to be eating a safe product. However, while several studies have been performed on the quality of foods processed by high pressure treatment at ambient temperature, the knowledge on the effect of HP/HT treatment is still limited. The NovelQ project partially filled this knowledge gap for a broad range of quality characteristics.

\section{Texture of plant-based foods}

Texture is one of the key quality attributes of fruit and vegetable based products, yet as a term, it is quite broad. It covers the structural and mechanical properties of a food and how these are perceived by vision, hearing and touching (Szczesniak, 2002). In edible fruits and vegetables, texture is mainly determined by the structure of their parenchyma cells which are weak and non-specialised. The structural integrity of the primary cell wall and middle lamella, in addition to the turgor pressure generated within the cells due to osmosis determine the texture of such tissues. Loss of this structural integrity, for instance during processing, can mainly be attributed to depolymerisation of cell wall pectic polysaccharides, leading to weakened cell adhesion.

During processing, pectin, particularly abundant in the middle lamella, is susceptible to both chemical and biochemical conversions that can either be beneficial (demethoxylation) or detrimental (depolymerisation) to the texture of the fruit or vegetable. This phenomenon has recently been reviewed (Duvetter et al., 2009; Sila et al., 2008; Sila et al., 2009; Van Buggenhout, Sila, Duvetter, Van Loey, \& Hendrickx, 2009).

Chemical demethoxylation of the esterified carboxyl groups in the homogalacturonan region at mild acid or alkaline conditions is enhanced both by temperature and pressure (Verlent et al., 2004). At low degree of methoxylation (DM), demethoxylation can also occur by acid hydrolysis, enhanced by temperature but not by pressure. At high $\mathrm{DM}$, during heating at neutral or alkaline $\mathrm{pH}$, betaeliminative depolymerisation leads to splitting of glycosidic linkages between galacturonic acid residues. As for acid hydrolysis, this reaction is enhanced by temperature but not by pressure. Besides these chemical modifications, the pectin structure can also be affected by the action of pectinases. For instance, pectin methylesterase hydrolyses methyl esters at C- 6 of the galacturonic acid residues in the homogalacturonan region, resulting in a demethoxylated pectin that can either cross-link with divalent ions such as calcium (firming effect) or is prone to the depolymerising action of polygalacturonase (softening effect). 
While the effect of high pressure processing at ambient pressure has been studied extensively, the number of investigations on the effect of HP/HT processing on texture is limited. In the NovelQ project, carrots were selected as a case-study as they have high pectin content and their textural changes largely depend on pectin modifications.

In an exploratory study on the effect of processing on texture of carrots, De Roeck et al. (2008) observed that although both heated (at 80 or $100^{\circ} \mathrm{C}$ ) and $\mathrm{HP} / \mathrm{HT}$ processed (at $80^{\circ} \mathrm{C}$ and $600 \mathrm{MPa}$ ) carrots showed an initial texture loss attributed to loss of turgor pressure, HP/HT treated carrots, unlike HT treated, did not undergo further softening as the process continued. Two possible explanations were suggested for the improved retention of hardness under pressure: (i) inhibition of the beta-eliminative depolymerisation, either directly by pressure or indirectly by the observed extensive demethoxylation and (ii) formation of fortifying networks of the low methoxylated pectin with endogenous $\mathrm{Ca}^{2+}$ ions. Another observation made by these authors is that while pectin from heat treated carrots showed better water solubility, high pressure treated carrots had a smaller water soluble pectin fraction in favour of the chelator soluble fraction. The latter can also be contributed to the extensive demethoxylation.

In another paper (De Roeck et al., 2009), these authors confirmed in pectin model systems that betaeliminative depolymerisation occurred at a lower rate and demethoxylation at a higher rate during $\mathrm{HP} / \mathrm{HT}$ processing $\left(90^{\circ} \mathrm{C}, 500-700 \mathrm{MPa}\right)$, in comparison to during heating at ambient pressure.

The retarding effect of pressure at elevated temperature on the texture of carrots was also demonstrated in a kinetic study (De Roeck, Mols, Duvetter, Van Loey, \& Hendrickx, 2010). Both for thermal $\left(95-105^{\circ} \mathrm{C}\right.$, maximal isothermal holding times ranging from $180-100 \mathrm{~min}$ ) and $\mathrm{HP} / \mathrm{HT}$ processing $\left(95-110^{\circ} \mathrm{C}, 600 \mathrm{MPa}\right.$, maximal isothermal holding times ranging from $\left.240-90 \mathrm{~min}\right)$, the changes in texture after processing could be described by a fractional conversion model. Although the residual level of hardness at long treatment times did not differ between treatments, the first order rate constants were significantly higher for heat treatment at ambient pressure (e.g. 0.2959 $\mathrm{min}^{-1}$ at $100^{\circ} \mathrm{C}$ and ambient pressure compared to $0.0289 \mathrm{~min}^{-1}$ for the same temperature at 600 $\mathrm{MPa}$ ). Nevertheless, the temperature dependence of the rate constants was quite similar for atmospheric and elevated pressure (activation energy of 152.12 and $176.79 \mathrm{~kJ} / \mathrm{mol}$, respectively). Extensive pectin demethoxylation during the HP/HT pre-process (heating to the initial temperature at ambient pressure and pressure build-up phase) could be responsible for a retarded betaelimination, which is considered to be the main cause of thermal softening of carrots. The formerly established pre-treatment strategy of lowering the DM and adding exogenous $\mathrm{Ca}^{2+}$ for texture improvement of thermally processed fruits and vegetables (Smout, Sila, Vu, Van Loey, \& Hendrickx, 2005), was also successful in case of HP/HT processing. However, an almost identical outcome was obtained by HP/HT treating the carrots directly in a calcium chloride solution without applying a pretreatment. Given the strong demethoxylation, the HP/HT dynamic build-up phase can be regarded as an implicit HP pre-treatment. Obviously, excluding a separate pre-treatment step will lead to time savings and a lower cost.

Furfaro et al. (2009b; 2009a) showed using two-dimensional NMR cross-correlation relaxometry in combination with optical microscopy that rapid pressurization to $600 \mathrm{MPa}$ immediately following a pre-cooking step at $60^{\circ} \mathrm{C}(20 \mathrm{~min})$ results in intact cell wall structure of both carrot phloem and xylem without evidence for cell wall separation or extracellular pectin-filled domains, while compartmentalized gelatinization does occur. This study also revealed that carrot phloem is richer in pectin that can be thermally or high pressure gelatinized than xylem, so that texture is more affected by processing in the former. This also suggests that in processed tissues, the texture is predominantly determined by cell wall strength and degree of biopolymer cross-linking rather than by turgor pressure. 
Finally, De Roeck et al. (2010) showed that for processing conditions leading to the same microbial impact, both for pasteurisation and sterilisation purposes, high pressure processes were the better option in retaining carrot hardness. In the case of HP pasteurization, only limited texture loss was observed as processing temperatures were not high enough to support beta-eliminative pectin degradation. Both thermal and HP sterilization processes were accompanied by significant hardness loss, although less pronounced in case of HP sterilization. The latter could be attributed to two effects: (i) faster heating and cooling rates corresponding to shorter treatment times and (ii) enhanced pectin demethoxylation during combined HP/HT processing resulting in low methoxylated pectin which is less susceptible to beta-eliminative depolymerisation and can form fortifying networks with $\mathrm{Ca} 2+$ present. This pronounced loss of texture was reflected in carrot microstructure where extensive cell separation and polymer solubilisation was observed. During consecutive storage of the treated carrots, the hardness did not change within 9 days.

The clear effect of HP/HT processing on the texture and structure will not only affect the consumer's appreciation of the food, but might also alter its nutrient bioavailability (Van Buggenhout et al., 2010; Knockaert et al., 2011). In conclusion, HP/HT processing leads the way to new and even unexpected or different textures and structures for products having the same microbial safety as those treated with conventional thermal processing.

\section{Health related compounds}

High pressure processing enhances reactions that are associated with a volume decrease. As the change in volume upon breaking of covalent bonds is small, its effect on low-molecular mass compounds such as vitamins is expected to be limited. This is corroborated by many studies, as reviewed by Oey et al. (2008b). Nevertheless, loss of nutritional value during consecutive storage occurs, for instance due to limited enzyme inactivation by high pressure. In HP/HT processing, the additional process parameter temperature can nonetheless be responsible for loss of nutrients, as shown by a limited number of studies prior to the NovelQ project (Taoukis et al., 1998; Kim, Park, Cho, \& Park, 2001; Oey, Verlinde, Hendrickx, \& Van Loey, 2006).

\section{Carrot and tomato carotenoids}

Dietary carotenoids are associated with reduction of the risk of various diseases, including certain cancers, cardiovascular disease and eye diseases (Krinsky \& Johnson, 2005, Britton, Pfander \& Liaaen-Jensen, 2009). The review paper by Oey et al. (2008b) already indicated that studies on carotenoid stability towards pressure are limited to ambient temperatures. These showed that carotenoids are relatively pressure stable and that extraction yields can be improved. In the NovelQ project, the processing window under investigation was expanded to HP/HT processing.

Carrots are a major source of $\alpha$-carotene, $\beta$-carotene and lutein. No major losses in $\alpha$-carotene or $\beta$-carotene occurred when carrot puree was heat-treated at atmospheric pressure $(0.1 \mathrm{MPa})$ at $40-$ $74^{\circ} \mathrm{C}$ or high pressure-treated at $800 \mathrm{MPa}$ and $40-74^{\circ} \mathrm{C}$. Lutein was slightly more sensitive to highpressure processing than $\alpha$ - or $\beta$-carotene. The lutein content of the carrot puree processed at 800 $\mathrm{MPa}$ and $74^{\circ} \mathrm{C}$ decreased to $80 \%$ of the content of the untreated puree, a level somewhat lower than that of carrot puree processed at atmospheric pressure $(0.1 \mathrm{MPa})$, which may partly be the result of adiabatic heating (up to $90^{\circ} \mathrm{C}$ ) during processing at $800 \mathrm{MPa}$ (Lille, 2008). These retentions are better than those reported by Kim and others (2001). At their strongest processing condition (10 min, 500 $\mathrm{MPa}, 70^{\circ} \mathrm{C}$ ), these authors observed a decrease of $78 \%$ and $65 \%$ of $\alpha$ - and $\beta$-carotene, respectively in carrot juice. Also in tomato puree, a major source of lycopene, no losses of this carotenoid were observed after a pressure treatment of $30 \mathrm{~min}$ at $800 \mathrm{MPa}$ and $55^{\circ} \mathrm{C}$ (Lille, 2008). This stability of lycopene to high pressure has been confirmed at even higher pressures in a recent study by Gupta, 
Balasubramaniam, Schwartz, \& Francis (2010), who showed increased extractability and limited isomerisation of all-trans lycopene from tomato juice after $\mathrm{HP} / \mathrm{HT}$ processing for 10 min at $100^{\circ} \mathrm{C}$ and $600 \mathrm{MPa}$. Nevertheless, this compound was prone to degradation during subsequent storage at $4^{\circ} \mathrm{C}$.

\section{Broccoli glucosinolates and derived products}

Since the review paper by Verhoeven et al. (1997), it is generally accepted that vegetables of the Brassicaceae family have a health promoting effect, mainly due to the presence of high concentrations of glucosinolates. Although the latter by themselves are biologically inactive their hydrolysis products show anti-carcinogenic potential. In intact tissue, myrosinase and glucosinolates are separated, necessitating cell disruption (for instance by processing) for the active hydrolysis products to be formed. However, the thermolabile enzyme is often already inactivated before the health related compounds are formed. On the other hand, strong hydrolysis is associated with bitter taste, calling for a good control of the myrosinase activity (Verkerk \& Dekker, 2004). Furthermore, any health related compound formed, such as isothiocyanates, needs to be stable during the process as well. The stability of both myrosinase and isothiocyanates under high pressure was poorly described with regard to kinetics prior to the NovelQ project (Ludikhuyze et al. 1999). Nevertheless, Houska et al. (2006) and Mandelová \& Totušek (2007) showed that high pressure treated broccoli juice possessed antimutagenic activity, which can affect the process of carcinogenesis.

In a series of papers, Van Eylen and co-workers (2007; 2008a; 2008b; 2009) investigated on a kinetic basis how the different aspects of the glucosinolate-myrosinase system could be affected through targeted $\mathrm{HP}$ processing $(100-600 \mathrm{MPa})$ at mild temperatures $\left(20-50^{\circ} \mathrm{C}\right)$ to obtain optimal formation and stability of the health related glucosinolate hydrolysis products. Myrosinase activity and inactivation, cell leakage and glucosinolate conversion reaction products were assessed. Preliminary experiments indicated that high pressure processing at high temperatures was not relevant for optimal functionality of this system.

In Figure 2, the integrated effect of HP processing at mild temperatures on the glucosinolatemyrosinase system is shown, based on the kinetic models obtained. At ambient temperature, up to $500 \mathrm{MPa}$ (points 1-4), little glucosinolate conversion occurs during processing. Processing conditions do not lead to sufficient cell leakage while myrosinase is still active. Under conditions of maximal myrosinase activity (point 5), little glucosinolate conversion occurs as cell leakage is limited. Increasing the pressure up to $300 \mathrm{MPa}$ at $40^{\circ} \mathrm{C}$ (points 6 and 7), leads to a higher degree of glucosinolate conversion as cell leakage increases even though myrosinase activity decreases. At even higher pressures (point 8 ), myrosinase becomes too unstable. Therefore, after subsequent incubation at room temperature, almost no glucosinolate conversion is observed. After processing at $100 \mathrm{MPa}$ (points 1 and 5), high glucosinolate conversion occurred, with more sulfurophane nitrile than sulfurophane being formed. After processing under conditions inducing cell leakage but without strongly affecting myrosinase activity (points 2, 3, 6 and 7), increased formation of sulfurophane was detected. Although some myrosinase inactivation occurred at $500 \mathrm{MPa}$ and $20^{\circ} \mathrm{C}$ (point 4), glucosinolates are still converted after processing and sulfurophane is strongly formed (Van Eylen, 2008). This figure clearly illustrates that, because of the different mechanisms under pressure and temperature, by proper selection of processing conditions specific hydrolysis products, with potentially higher health beneficial effects can be obtained in pressure processed broccoli. This is of course less relevant for broccoli-based juices. In this case, the myrosinase comes into contact with its substrate after mixing. During, for instance, a following pasteurization step with high pressure, the hydrolysis products are relatively stable.

\section{Strawberry anthocyanins}


In addition to being responsible for the red colour of strawberries, anthocyanins are important due to their role as bioactive antioxidants. These compounds are relatively stable during HP processing at moderate temperature, although this treatment can not prevent their enzymatic degradation during storage because of insufficient inactivation of the endogenous enzymes (peroxidase, polyphenol oxidase and $\beta$-glucosidase) involved in these reactions (Zabetakis, Koulentianos, Orruno, \& Boyes, 2000; Garcia-Palazon, Suthanthangjai, Kajda, \& Zabetakis, 2004; Patras, Brunton, Da Pieve, \& Butler, 2009).

At higher temperature $\left(65^{\circ} \mathrm{C}\right)$, HP processing $(300-700 \mathrm{MPa})$ only slightly changes the colour of strawberry juice at its natural $\mathrm{pH} 3.7$, suggesting that anthocyanins are only slightly affected (Rodrigo, Van Loey, \& Hendrickx, 2007). This was confirmed and elucidated in the NovelQ study by Lille et al. (2011) on strawberry purée. Anthocyanins were not markedly affected by high pressure processing (400 or $800 \mathrm{MPa}$ ) at ambient temperature, but at $60{ }^{\circ} \mathrm{C}(20 \mathrm{~min}$ ) the content of anthocyanins decreased somewhat. Pelargonidin-3-succinylglucoside was most sensitive to pressure processing. Its content decreased to about $65 \%$ after a 10 min treatment at $800 \mathrm{MPa}$ and $60^{\circ} \mathrm{C}$. These authors could not attribute the loss of anthocyanin content to one specific factor (heat, oxidation, enzymatic activity), although they could exclude the formation of less stable anthocyanidins due to $\beta$-glucosidase activity as no clear aglycon peaks were observed in the HPLC chromatograms of the strawberry samples.

Verbeyst et al. (2010) compared the degradation kinetics of the major anthocyanin in strawberry paste (pelargonidin-3-glucoside) during HP/HT treatments $\left(80-130^{\circ} \mathrm{C}\right.$ and a pressure range of $200-$ $700 \mathrm{MPa}$ ) to similar temperature conditions at ambient pressure. For all processes, the degradation of pelargonidin-3-glucoside followed a first-order kinetic model. These authors observed a positive effect of both temperature and pressure on the degradation rate, although the effect of increasing pressure was smaller than that of increasing temperature. Temperature dependence of the degradation rate constants, described by the Arrhenius equation, was higher at atmospheric pressure than at elevated pressures, where all activation energies were comparable. Activation volumes, estimated by the Eyring equation, demonstrated only a small pressure dependence of the reaction rate constants. A model describing the combined temperature-pressure dependence of the degradation rate constants was proposed as a tool to design and optimize HPHT processes. Although pressure plays an additional role in enhancing the degradation rate of anthocyanins, the shorter treatment times during these processes (due to fast heating and cooling rates), might lead to a lower integrated process impact in comparison to an equivalent thermal process.

In conclusion, while high pressure processing at ambient temperature has a limited effect on health related compounds; the additional process parameter temperature in HP/HT processing can induce losses in some nutrients. This strongly depends on the type of nutrient. The results obtained within the NovelQ project suggest that fat soluble nutrients are less sensitive to HP/HT processing than water soluble, at least for the ones studied.

\section{Flavour}

Flavour is the sensory impression of a food that is determined mainly by taste and smell. Even small changes in the flavour-active components can alter the overall flavour of the fruit or vegetable to a large extent. High-pressure as such is considered to have a limited effect on low-molecular-weight flavour compounds, but as on health-related compounds, high-pressure processing may result in undesired changes in the overall flavour of plant-based foods for example during storage if enzyme inactivation has been incomplete. Although several studies have been performed describing the limited change in flavour immediately after high pressure treatment of fruit and vegetable products, 
as reviewed by Oey et al. (2008a), in only one was the additional effect of temperature considered (Krebbers, Matser, Koets, Bartels, \& Van Den Berg, 2002).

\section{Strawberry flavour}

The typical flavour of strawberries is contributed to a complex mixture of furanones, esters, aldehydes, alcohols and sulphur compounds. Some compounds have a greater impact on overall flavour than others due to differences in the characteristic odour thresholds of the compounds. Previous studies (Lambert, Demazeau, Largeteau, \& Bouvier, 1999; Zabetakis et al., 2000) have shown that high pressure treatment does induce some changes in the amounts of volatile compounds, although to a lesser extent than thermal processing, and probably due to insufficient enzyme inactivation. However, because of differences in odour thresholds, these changes might exert only a limited effect on the actual appreciation of the overall strawberry flavour. Furthermore, there are no known studies on the combined effect of pressure and temperature on this quality attribute.

Combing descriptive sensory analysis, GC-olfactometry and GC-MS of volatile compounds, Lille et al. (2011) concluded that HP/HT treatment affects the overall flavour of strawberry purée. They were able to link many of the volatile compounds to specific verbal descriptions. Nevertheless, there were some descriptions that remained without a positively identified volatile, probably due to differences in odour threshold and GC-MS detection limits.

HP-processing at the most intense conditions (10 min at $800 \mathrm{MPa}, 60^{\circ} \mathrm{C}$ ) resulted in a clear increase in dried fruit- and tea-like odour and a loss in acidity (Figure 3 ). The odour of the strawberry purée treated at $800 \mathrm{MPa}$ at ambient temperature was perceived very similar to that of the untreated purée $\left(0.1 \mathrm{MPa}, 20^{\circ} \mathrm{C}\right)$.

An intense resin or dried fruit resembling odour was also detected by GC-olfactometry in the strawberry samples treated at $60^{\circ} \mathrm{C}$ (for $10 \mathrm{~min}$ at 0.1 or $800 \mathrm{MPa}$ ). This odorous event also appeared in the sample treated at $800 \mathrm{MPa}, 20^{\circ} \mathrm{C}$, but at a lower intensity. The volatile compound responsible for the dried fruit-like odour remained, however, unknown.

GC-MS revealed that high-pressure processing at $800 \mathrm{MPa}$ (for $10 \mathrm{~min}$ at 20 or $60^{\circ} \mathrm{C}$ ), as well as heating at $60{ }^{\circ} \mathrm{C}$ at atmospheric pressure $(10 \mathrm{~min})$, resulted in increased concentrations of many aldehyde and ketone compounds, which are typical lipid oxidation reaction products. Lipid oxidation is initiated already when the strawberries are homogenised, but it appeared to be enhanced during processing at the above mentioned conditions. Many of the aldehydes, which showed increased concentrations due to high-pressure processing at $20^{\circ} \mathrm{C}$, are known to be responsible for green or grass-like notes. An increase in the intensity of green notes in the high-pressure processed samples was also detected by GC-olfactometry, but not in the sensory evaluation of overall odour. This might be due to the fact that GC-olfactometry splits the odour to its odorous components, whereas the overall odour is perceived as its entity in sensory assessment.

High-pressure processing at $800 \mathrm{MPa}\left(10 \mathrm{~min}\right.$ at 20 or $\left.60^{\circ} \mathrm{C}\right)$ did not, according to GC-MS, cause significant losses in ester compounds, which are important compounds in fresh strawberries since they are responsible for fruity and sweet notes in the overall flavour. By GC-olfactometry, however, a reduction in the intensity of fruity notes was detected as a result of high-pressure processing (10 min at $800 \mathrm{MPa}, 20$ or $\left.60^{\circ} \mathrm{C}\right)$ or heating at $60^{\circ} \mathrm{C}(10 \mathrm{~min}$ at $0.1 \mathrm{MPa})$.

By GC-olfactometry, an additional metallic odour was detected in the high-pressure processed strawberry purée $\left(10 \mathrm{~min}\right.$ at $800 \mathrm{MPa}, 20^{\circ} \mathrm{C}$ and $\left.60^{\circ} \mathrm{C}\right)$. This odour was absent in the untreated $(0.1$ 
$\mathrm{MPa}, 20^{\circ} \mathrm{C}$ ) and heat-treated $\left(10 \mathrm{~min}\right.$ at $0.1 \mathrm{MPa}, 60^{\circ} \mathrm{C}$ ) samples. The compound(s) responsible for the metallic odour could not be identified in the study.

In conclusion, HP/HT processing does not appear to be the ideal substitute for thermal processing with regard to strawberry flavour.

\section{Tomato flavour}

More than 30 volatiles (e.g. Z-3-hexenal, Z-3-hexanol, hexanal, 1-penten-3-one, 3-methylbutanal, E2-hexenal, 6-methyl-5-hepten-2-one, methyl salicylate, 2 -isobutylthiazole and $\beta$-ionone) have been identified that probably contribute to the typical tomato flavour. The flavour is not only directly reflected by the sum of the volatile and non-volatile components, but also depends on their relative amounts and interactions (Buttery, Teranishi, \& Ling, 1987; Buttery, 1993). The knowledge on the effect of high pressure processing on the flavour of tomato is limited, although the concentration of hexanal, has been shown to increase due to high pressure treatment, leading to a rancid aroma (Porretta, Birzi, Ghizzoni, \& Vicini, 1995). Lipoxygenase and hydroperoxide lyase, naturally present in many vegetables and fruits, were held partially responsible for the increased concentration of this lipid derived volatile compound (Oey et al., 2008a).

In the NovelQ project, Viljanen et al. (2011) observed that the effect of HP/HT processing on the amount of volatile compounds could mainly be attributed to the heat treatment rather than to the high pressure treatment itself. The levels of most aldehydes decreased as the temperature increased $\left(20^{\circ} \mathrm{C}\right.$ to $60^{\circ} \mathrm{C}, 10 \mathrm{~min}$ treatment). Most significant decreases were observed in hexanal, E-2-hexenal and 1-penten-3-one, which are important volatiles in fresh tomato flavour. In tomato purée treated at $800 \mathrm{MPa}\left(20^{\circ} \mathrm{C}\right.$ and $\left.60^{\circ} \mathrm{C}\right)$ for $10 \mathrm{~min}$ a reduction in the intensity of fresh tomato odour was coupled with a decrease in the amounts of enal aldehydes, 1-penten-3-one, 1-penten-3-ol, 1pentanol and 2-pentylfuran. Simultaneously with the loss of fresh tomato odour, an increased intensity of cooked tomato odour and tea aroma was perceived in samples treated for $10 \mathrm{~min}$ at 800 $\mathrm{MPa}$ and $60^{\circ} \mathrm{C}$. On the basis of the observed changes in volatile composition and perceived odour, the authors concluded that high-pressure processing, at least under the conditions studied, is not suitable for preserving fresh tomato flavour.

\section{Conclusions}

High pressure/high temperature processing exerts a broad range of effects on different quality and safety aspects. While it has positive effects on the inactivation of some food allergens, the mitigation of acrylamide and the texture of plant-based foods and does not affect the carotenoid content, it can have a detrimental effect on overall flavour and some water soluble health related compounds. However, to make a fair comparison with conventional thermal processing, the effect on quality and (bio)chemical safety needs to be evaluated on an equivalent basis with regard to microbial safety. $\mathrm{HP} / \mathrm{HT}$ processing is most likely to be used in in-pack processing rather than for processing of liquids, for which UHT processing proves economically more feasible. Nevertheless, as it strongly reduces treatment times due to high heating rates, it offers a UHT-like solution for slowly heating foods. In addition to the high heating rates, the technology is also characterised by fast cooling, which is unlike other fast heating methods such as ohmic heating. As a result, products with better quality can be obtained in comparison to conventional in-pack thermal processing, even for quality aspects where pressure and temperature exert a synergistic detrimental effect. 


\section{Future research demands}

Based on their results and findings, the researchers in the NovelQ project have identified some major points requiring further attention in order to fully understand of the effect of $\mathrm{HP} / \mathrm{HT}$ processing on the quality and safety of food products.

1. Proper experimental set-up and description thereof is vital to compare kinetic information obtained by research groups. The proportion between the processing time (including pressure build-up time, holding time, temperature equilibration time) and the time constants of the kinetics (microbe, enzyme, nutrient) complicate model discrimination for kinetics. In case of fast inactivation kinetics, the processing-induced changes can be masked by the dynamic processing effects if not properly taken into account during the data analysis.

2. The effect of HP/HT on chemical risk reactions such as acrylamide formation also needs to be studied in matrices of lower water content. Furthermore, there is a need for "in vitro" tests for toxicological assessment of HP/HT treated foods.

3. The influence of the food matrix as well as the mechanism of allergen reduction by HP/HT need to be further elucidated.

4. The consequences of the different food textures obtained during HP/HT processing on the nutrient bio-accessibility need to be determined.

5. In order to completely grasp the effect of HP/HT processing on flavour and colour, mechanistic insight in flavour development and colour changes during post-treatment storage is required.

6. Comparison between HP/HT processing and conventional thermal processing needs to be made for processing conditions that result in equivalent microbial safety.

7. HP/HT processing can also be considered outside the scope of preservation technology. It is a tool to obtain new and different structures and functions. In that respect, the process-structurefunction relations need to be elucidated. An example for this field of research is pectin management through processing and how the resulting structure-function relation affects rheology and nutrient accessibility.

\section{Acknowledgement}

This work was financially supported by the Commission of the European Communities, Framework 6, Priority 5 'Food Quality and Safety', Integrated Project NovelQ FP6-CT-2006-015710 and the Katholieke Universiteit Leuven. 


\section{References}

Ahn, J., Balasubramaniam, V.M., \& Yousef, A.E. (2007) Inactivation kinetics of selected aerobic and anaerobic bacterial spores by pressure-assisted thermal processing. International Journal of Food Microbiology, 113, 321329.

Alt, N. \& Schieberle, P. (2005). Identification of N-7-(1-carboxyethyl)-arginine, a novel posttranslational protein modification of arginine formed at high hydrostatic pressure. Maillard Reaction: Chemistry at the Interface of Nutrition, Aging, and Disease, 1043, 55-58.

Bell, L. N. (1997). Maillard reaction as influenced by buffer type and concentration. Food Chemistry, 59, 143147.

Britton, G., Pfander, H. \& Liaaen-Jensen, S. eds. (2009) Carotenoids. Volume 5. Nutrition and Health. Birkhäuser Verlag. $431 \mathrm{pp}$

Bruins, M. E., Matser, A. M., Janssen, A. E. A., \& Boom, R. M. (2007). Buffer selection for HP treatment of biomaterials and its consequences for enzyme inactivation studies. High Pressure Research, 27, 101-107.

Buttery, R. G. (1993). Quantitative and sensory aspects of flavor of tomato and other vegetables and fruits. In T. Acree \& R. Teranishi (Eds.), Flavor Science: Sensible Principles and Techniques (pp. 259-286). Washington: ACS.

Buttery, R. G., Teranishi, R., \& Ling, L. C. (1987). Fresh Tomato Aroma Volatiles - A Quantitative Study. Journal of Agricultural and Food Chemistry, 35, 540-544.

Byrne, R. H. \& Laurie, S. H. (1999). Influence of pressure on chemical equilibria in aqueous systems - With particular reference to seawater. Pure and Applied Chemistry, 71, 871-890.

De Roeck, A., Mols, J., Duvetter, T., Van Loey, A., \& Hendrickx, M. (2010). Carrot texture degradation kinetics and pectin changes during thermal versus high-pressure/high-temperature processing: A comparative study. Food Chemistry, 120, 1104-1112.

De Roeck, A., Mols, J., Sila, D. N., Duvetter, T., Van Loey, A., \& Hendrickx, M. (2010). Improving the hardness of thermally processed carrots by selective pretreatments. Food Research International, 43, 1297-1303.

De Roeck, A., Duvetter, T., Fraeye, I., Van der Plancken, I., Sila, D. N., Van Loey, I. A. et al. (2009). Effect of highpressure/high-temperature processing on chemical pectin conversions in relation to fruit and vegetable texture. Food Chemistry, 115, 207-213.

De Roeck, A., Sila, D. N., Duvetter, T., Van Loey, A., \& Hendrickx, M. (2008). Effect of high pressure/high temperature processing on cell wall pectic substances in relation to firmness of carrot tissue. Food Chemistry, $107,1225-1235$.

De Vleeschouwer, K., Van der Plancken, I., Van Loey, A., \& Hendrickx, M. E. (2010). The effect of high pressurehigh temperature processing conditions on acrylamide formation and other Maillard reaction compounds. Journal of Agricultural and Food Chemistry, 58, 11740-11748.

Delgado, A., Rauh, C., Kowalczyk, W., \& Baars, A. (2008). Review of modelling and simulation of high pressure treatment of materials of biological origin. Trends in Food Science \& Technology, 19, 329-336.

Deters, F., Hofmann, T., \& Schieberle, P. (2003). Influence of high hydrostatic pressure on the formation of key Maillard-type flavour compounds from D-glucose and L-proline. Advances in High Pressure Bioscience and Biotechnology li, Proceedings, 347-350. 
Duvetter, T., Sila, D. N., Van Buggenhout, S., Jolie, R., Van Loey, A., \& Hendrickx, M. (2009). Pectins in Processed Fruit and Vegetables: Part I-Stability and Catalytic Activity of Pectinases. Comprehensive Reviews in Food Science and Food Safety, 8, 75-85.

Frank, O., Heberle, I., Schieberle, P., \& Hofmann, T. (2002). Influence of high hydrostatic pressure on the formation of intense chromophores formed from pentoses and primary amino acids. Maillard Reaction in Food Chemistry and Medical Science: Update for the Postgenomic Era, 1245, 387-388.

Furfaro, M. E., Marigheto, N., Moates, G. K., Cross, K., Parker, M. L., Waldron, K. W. et al. (2009a). Multidimensional NMR cross-correlation relaxation study of carrot phloem and xylem. Part II: Thermal and high-pressure processing. Applied Magnetic Resonance, 35, 537-547.

Furfaro, M. E., Marigheto, N., Moates, G. K., Cross, K., Parker, M. L., Waldron, K. W. et al. (2009b). Multidimensional NMR cross-correlation relaxation study of carrot phloem and xylem. Part I: Peak assignment. Applied Magnetic Resonance, 35, 521-535.

Garcia-Palazon, A., Suthanthangjai, W., Kajda, P., \& Zabetakis, L. (2004). The effects of high hydrostatic pressure on beta-glucosidase, peroxidase and polyphenoloxidase in red raspberry (Rubus idaeus) and strawberry (Fragaria x ananassa). Food Chemistry, 88, 7-10.

Grauwet, T., Van der Plancken, I., Vervoort, L., Van Loey, A., \& Hendrickx, M. (2011). Temperature uniformity mapping in a high pressure high temperature reactor by process impact evaluation on a temperature sensitive indicator. Journal of Food Engineering105, 36-47.

Gupta, R., Balasubramaniam, V. M., Schwartz, S. J., \& Francis, D. M. (2010). Storage Stability of Lycopene in Tomato Juice Subjected to Combined Pressure-Heat Treatments. Journal of Agricultural and Food Chemistry, $58,8305-8313$.

Heberle, I., Schieberle, P., \& Hofmann, T. (2003). Influence of high hydrostatic pressure on the formation of non-enzymatic browning products formed in Maillard-type reactions. Advances in High Pressure Bioscience and Biotechnology li, Proceedings, 341-345.

Heroldova, M., Houska, M., Vavrova, H., Kucera, P., Setinova, I., Honzova, S. et al. (2009). Influence of highpressure treatment on allergenicity of rDau $\mathrm{c} 1$ and carrot juice demonstrated by in vitro and in vivo tests. High Pressure Research, 29, 695-704.

Hill, V. M., Ledward, D. A., \& Ames, J. M. (1996). Influence of high hydrostatic pressure and pH on the rate of maillard browning in a glucose-lysine system. Journal of Agricultural and Food Chemistry, 44, 594-598.

Houska, M., Kminkova, M., Strohalm, J., Setinova, I., Heroldova, M., Novotna, P. et al. (2009). Allergenicity of main celery allergen rApi g1 and high-pressure treatment. High Pressure Research, 29, 686-694.

Husband, F. A., Aldick, T., Van der Plancken, I., Grauwet, T., Skypala, I., Mackie, A. (2010). High pressure treatment reduces the allergenicity of the major allergens in apple and celeriac. Molecular and Nutrition and Food Research. In press. doi: 10.1002/mnfr.201000566

Jaeger, H., Janositz, A., \& Knorr, D. (2010). The Maillard reaction and its control during food processing. The potential of emerging technologies. Pathologie Biologie, 58, 207-213.

Johnson, P. E., Van der Plancken, I., Balasa, A., Husband, F. A., Grauwet, T., Hendrickx, M. et al. (2010). High pressure, thermal and pulsed electric-field-induced structural changes in selected food allergens. Molecular Nutrition and Food Research, 54, 1701-1710.

Kim, Y. S., Park, S. J., Cho, Y. H., \& Park, J. (2001). Effects of combined treatment of high hydrostatic pressure and mild heat on the quality of carrot juice. Journal of Food Science, 66, 1355-1360. 
Knockaert, G., De Roeck, A., Lemmens, L., Van Buggenhout, S., Hendrickx, M., \& Van Loey, A. (2011). Effect of thermal and high pressure processes on structural and health-related properties of carrots (Daucus carota). Food Chemistry, 125, 903-912.

Krebbers, B., Matser, A., Koets, M., Bartels, P., \& Van Den Berg, R. (2002). High pressure-temperature processing as an alternative for preserving basil. High Pressure Research, 22, 711-714.

Krinsky, N.I \& Johnson, E.J. (2005) Carotenoid actions and their relation to health and disease. Molecular Aspects of Medicine, 26, 459-516.

Lambert, Y., Demazeau, G., Largeteau, A., \& Bouvier, J. M. (1999). Changes in aromatic volatile composition of strawberry after high pressure treatment. Food Chemistry, 67, 7-16.

Landfeld, A., Matser, A., Strohalm, J., Oey, I., Van der Plancken, I., Grauwet, T. et al. (2010). Can we qualitatively obtain the same time-temperature history using different pilot HP units? Innovative Food Science \& Emerging Technologies, submitted paper.

Lille, M. (2008). Unpublished results.

Lille, M., Viljanen, K., Heiniö, R.-L., \& Buchert, J. (2011). Impact of high-pressure processing on volatile composition and odour of strawberry purée. Unpublished results.

Meyer-Pittroff, R., Behrendt, H., \& Ring, J. (2007) Specfic immuno-modulation and therapy by means of high pressure treated allergens. High pressure research, 27, 63-67.

Moreno, F. J., Molina, E., Olano, A., \& Lopez-Fandino, R. (2003). High-pressure effects on Maillard reaction between glucose and lysine. Journal of Agricultural and Food Chemistry, 51, 394-400.

Oey, I., Verlinde, P., Hendrickx, M., \& Van Loey, A. (2006). Temperature and pressure stability of L-ascorbic acid and/or [6s] 5-methyltetrahydrofolic acid: A kinetic study. European Food Research and Technology, 223, 71-77.

Oey, I., Lille, M., Van Loey, A., \& Hendrickx, M. (2008a). Effect of high-pressure processing on colour, texture and flavour of fruit- and vegetable-based food products: a review. Trends in Food Science \& Technology, 19, 320-328.

Oey, I., Van der Plancken, I., Van Loey, A., \& Hendrickx, M. (2008b). Does high pressure processing influence nutritional aspects of plant based food systems? Trends in Food Science \& Technology, 19, 300-308.

Patras, A., Brunton, N. P., Da Pieve, S., \& Butler, F. (2009). Impact of high pressure processing on total antioxidant activity, phenolic, ascorbic acid, anthocyanin content and colour of strawberry and blackberry purees. Innovative Food Science \& Emerging Technologies, 10, 308-313.

Porretta, S., Birzi, A., Ghizzoni, C., \& Vicini, E. (1995). Effects of Ultra-High Hydrostatic-Pressure Treatments on the Quality of Tomato Juice. Food Chemistry, 52, 35-41.

Ramaswamy, H.S., Shao, Y., and Zhu, S. (2010) High pressure destruction kinetics of Clostridium sporogenes ATCC11437 spores in milk at elevated quasi-isothermal conditions. Journal of Food Engineering, 96, $249-257$.

Reineke, K., Mathys, A., Knorr, D. (2011) The impact of high pressure and temperature on bacterial spores: inactivation mechanisms of Bacillus subtilis above 500 MPa. Journal of Food Science, 76, M189-M197.

Rizzi, G. P. (2004). Role of phosphate and carboxylate ions in Maillard browning. Journal of Agricultural and Food Chemistry, 52, 953-957. 
Rodrigo, D., Van Loey, A., \& Hendrickx, M. (2007). Combined thermal and high pressure colour degradation of tomato puree and strawberry juice. Journal of Food Engineering, 79, 553-560.

Schwarzenbolz, U., Klostermeyer, H., \& Henle, T. (2000). Maillard-type reactions under high hydrostatic pressure: formation of pentosidine. European Food Research and Technology, 211, 208-210.

Setinova, I., Kminkova, M., Strohalm, J., Heroldova, M., Novotna, P., Honzova, S. et al. (2009). Allergenicity of main birch allergen rBet v1 and high-pressure treatment. High Pressure Research, 29, 680-685.

Shao, Y., Zhu, S., Ramaswamy, H.S. \& Marcotte, M. (2010) Compression heating and temperature control for high-pressure destruction of bacterial spores: an experimental method for kinetics evaluation. Food and Bioprocess Technology. 3, 71-78.

Sila, D. N., Duvetter, T., De Roeck, A., Verlent, I., Smout, C., Moates, G. K. et al. (2008). Texture changes of processed fruits and vegetables: potential use of high-pressure processing. Trends in Food Science \& Technology, 19, 309-319.

Sila, D. N., Van Buggenhout, S., Duvetter, T., Fraeye, I., De Roeck, A., Van Loey, A. et al. (2009). Pectins in Processed Fruits and Vegetables: Part II-Structure-Function Relationships. Comprehensive Reviews in Food Science and Food Safety, 8, 86-104.

Smout, C., Sila, D. N., Vu, T. S., Van Loey, A. M. L., \& Hendrickx, M. E. G. (2005). Effect of preheating and calcium pre-treatment on pectin structure and thermal texture degradation: a case study on carrots. Journal of Food Engineering, 67, 419-425.

Somkuti, J., Houska, M. \& Smeller, L. (2011) Pressure and temperature stability of main apple allergen Mal d1. European Biophysical Journal, 40, 143-151.

Szczesniak, A. S. (2002). Texture is a sensory property. Food Quality and Preference, 13, 215-225.

Taoukis, P. S., Panagiotidis, P., Stoforos, N. G., Butz, P., Fister, H., \& Tauscher, B. (1998). Kinetics of vitamin C degradation in under high pressure-moderate temperature processing in model systems and fruit juices. In $\mathrm{N}$. S. Isaacs (Ed.), High pressure food science, bioscience and chemistry (pp. 310-316). Cambridge: The Royal Society of Chemistry.

Van Buggenhout, S., Alminger, M., Lemmerns, L., Colle, I., Knockaert, G., Moelants, K. et al. (2010). In vitro approaches to estimate the effect of food processing on carotenoid availability need thorough understanding of processing induced microstructural changes. Trends in Food Science \& Technology, 21, 607-618.

Van Buggenhout, S., Sila, D. N., Duvetter, T., Van Loey, A., \& Hendrickx, M. (2009). Pectins in Processed Fruits and Vegetables: Part III-Texture Engineering. Comprehensive Reviews in Food Science and Food Safety, 8, 105117.

Van der Plancken, I., Grauwet, T., Oey, I., Van Loey, A., \& Hendrickx, M. (2008). Impact evaluation of high pressure treatment on foods: considerations on the development of pressure-temperature-time integrators (pTTIs). Trends in Food Science \& Technology, 19, 337-348.

Van Eylen, D. (2008). Effect of high pressure/temperature processing on the myrosinase-glucosinolate system in broccoli. PhD thesis, Katholieke Universiteit Leuven, Leuven, Belgium.

Van Eylen, D., Bellostas, N., Strobel, B. W., Oey, I., Hendrickx, M., Van Loey, A. et al. (2009). Influence of pressure/temperature treatments on glucosinolate conversion in broccoli (Brassica oleraceae L. cV Italica) heads. Food Chemistry, 112, 646-653. 
Van Eylen, D., Oey, I., Hendrickx, M., \& Van Loey, A. (2007). Kinetics of the stability of broccoli (Brassica oleracea cv. Italica) myrosinase and isothiocyanates in broccoli juice during pressure/temperature treatments. Journal of Agricultural and Food Chemistry, 55, 2163-2170.

Van Eylen, D., Oey, I., Hendrickx, M., \& Van Loey, A. (2008a). Effects of pressure/temperature treatments on stability and activity of endogenous broccoli (Brassica oleracea L. cv. Italica) myrosinase and on cell permeability. Journal of Food Engineering, 89, 178-186.

Van Eylen, D., Oey, I., Hendrickx, M., \& Van Loey, A. (2008b). Behavior of mustard seed (Sinapis alba L.) myrosinase during temperature/pressure treatments: a case study on enzyme activity and stability. European Food Research and Technology, 226, 545-553.

Verbeyst, L., Oey, I., Van der Plancken, I., Hendrickx, M., \& Van Loey, A. (2010). Kinetic study on the thermal and pressure degradation of anthocyanins in strawberries. Food Chemistry, 123, 269-274.

Verhoeven, D. T. H., Verhagen, H., Goldbohm, R. A., van den Brandt, P. A., \& van Poppel, G. (1997). A review of mechanisms underlying anticarcinogenicity by brassica vegetables. Chemico-Biological Interactions, 103, 79129.

Verkerk, R., \& Dekker, M. (2004) Glucosinolates and myrosinase activity in red cabbage (Brassica oleracea L. Var. Capitata f. rubra DC.) after various microwave treatments. Journal of Agricultural and Food Chemistry, 52, 7318-7323.

Verlent, I., Van Loey, A., Smout, C., Duvetter, T., Nguyen, B. L., \& Hendrickx, M. E. (2004). Changes in purified tomato pectinmethyl-esterase activity during thermal and high pressure treatment. Journal of the Science of Food and Agriculture, 84, 1839-1847.

Viljanen, K., Lille, M., Heiniö, R.-L., \& Buchert, J. (2011). Effect of high-pressure processing on volatile composition and odour of cherry tomato purée. Food Chemistry, submitted paper.

Wilson, D. R., Dabrowski, L., Stringer, S., Moezelaar, R., \& Brocklehurst, T. F. (2008). High pressure in combination with elevated temperature as a method for the sterilisation of food. Trends in Food Science \& Technology, 19, 289-299.

Jankiewicz, A., Baltes, W., Bogl, K.W., Dehne, L.I., Jamin, A., Hoffmann, A., Haustein, D., Vieths, S. (1997) Influence of food processing on the immunochemical stability of celery allergens. Journal of the Science of Food and Agrculture, 75, 359-370.

Zabetakis, I., Koulentianos, A., Orruno, E., \& Boyes, I. (2000). The effect of high hydrostatic pressure on strawberry flavour compounds. Food Chemistry, 71, 51-55.

Zhu, S., Naim, F., Marcotte, M., Ramaswamy, H. \& Shao, Y. (2008) High pressure destruction kinetics of Clostridium sporogenes spores in ground beef at elevated temperatures. International Journal of Food Microbiology, 126, 86-92. 


\section{List of Figures}

Figure 1 Example of a temperature (red) and pressure (blue) profile resulting from the proposed strategy. Protocol steps consist of (1)equilibration of the pressure vessel to the process temperature $T_{p}$ (2)insertion of sample in isolated sample holder in the vessel and heating of the sample (3) to initial temperature $T_{i}$ (experimentally determined and dependent on pressure and required $T_{p}$ ) followed by $(4)$ fast pressure build-up accompanied by adiabatic heating. (5) The sample temperature is allowed to equilibrate to $T_{p}(6)$ and the sample is subjected to isothermal-isobaric conditions during the treatment time, after which (7) pressure is released, which is associated with a fast temperature drop. Adapted from, for instance, Grauwet et al. (2010).

Figure 2 Overlay of isorate contour plots for myrosinase activity (green), cell leakage (black) and myrosinase inactivation (red). Selected processing conditions (numbers) are described in the text. Van Eylen (2008) with permission.

Figure 3 Sensory profile of the perceived odour of strawberry purée ( $n=2 \times 12)$. 